\title{
Dietary intake of polyphenol and potassium in the management of Type 2 Diabetes Mellitus Subjects with Chronic Kidney Disease
}

\author{
S.A. Palma-Duran, M.E.J. Lean and E. Combet \\ Human Nutrition, School of Medicine, University of Glasgow, G31 2ER, UK
}

Chronic kidney disease (CKD) is a major complication of type 2 Diabetes Mellitus (T2DM). Approximately a third of T2DM patients will develop CKD, increasing their risk of all-cause mortality by $3-19 \%{ }^{(1)}$. Polyphenolics are dietary factors potentially able to prevent damage in the kidney, through inhibition of glycation, reduction of uremic damage, and increased radical-scavenging activity $^{(2)}$. Polyphenolics-rich products (including fruit and vegetables) are sometime restricted in CKD patients to reduce the risk of hyperkalaemia (serum $>5.5 \mathrm{mM}$ ), but it is not clear how widespread this is. In the early stages of CKD $\left(\mathrm{GFR}>30 \mathrm{~mL} / \mathrm{min}^{\circ} 1.72 \mathrm{~m}{ }^{2}\right.$ ), a diet high in fruits and vegetables may delay CKD progression ${ }^{(3)}$; however, studies about the dietary habits of CKD patients (before dialysis) are lacking and hamper recommendations in this patient group. The aim of the present study was to estimate polyphenolics and potassium intake in T2DM patients with CKD stage 3, and in matched healthy controls.

The cross-sectional study included 87 T2DM subjects with CKD stage 3 as cases and 87 healthy adults matched by age and gender as controls. Polyphenolics and potassium intake was estimated using the EPIC-Norfolk food frequency questionnaire and liquids intake with a beverage questionnaire. The Kawasaki formula ${ }^{(4)}$ was used to estimate 24-hour urinary potassium excretion from a spot urine sample.

\begin{tabular}{|c|c|c|c|c|c|c|c|}
\hline & \multicolumn{3}{|c|}{ Cases $(n=87)$} & \multicolumn{3}{|c|}{ Controls $(n=87)$} & \multirow[b]{2}{*}{$\mathrm{p}$-value } \\
\hline & Median & $\mathrm{P} 25^{\text {th }}$ & $\mathrm{P} 75^{\text {th }}$ & Median & $\mathrm{P} 25^{\text {th }}$ & $\mathrm{P} 75^{\text {th }}$ & \\
\hline Age (years)* & 68 & $9 \cdot 0$ & - & 68 & $9 \cdot 0$ & - & 0.94 \\
\hline BMI $\left(\mathrm{kg} / \mathrm{m}^{2}\right)$ & $34 \cdot 2$ & $29 \cdot 8$ & $38 \cdot 2$ & $29 \cdot 1$ & $26 \cdot 0$ & $32 \cdot 0$ & 0.00 \\
\hline eGFR (mL/min/1.73 $\left.\mathrm{m}^{2}\right)$ & $46 \cdot 3$ & $36 \cdot 0$ & $53 \cdot 4$ & $84 \cdot 7$ & $76 \cdot 6$ & $93 \cdot 9$ & 0.00 \\
\hline Serum potassium (mM) & $4 \cdot 68$ & $4 \cdot 30$ & 4.90 & $4 \cdot 29$ & $4 \cdot 10$ & $4 \cdot 50$ & $0 \cdot 00$ \\
\hline Urinary potassium $(\mathrm{mmol} / \mathrm{d})$ & $88 \cdot 1$ & $71 \cdot 0$ & $101 \cdot 0$ & $97 \cdot 0$ & 62.9 & 83.8 & $0 \cdot 05$ \\
\hline Energy $(\mathrm{kcal} / \mathrm{d})$ & $1732 \cdot 2$ & $1211 \cdot 6$ & $1911 \cdot 1$ & $1846 \cdot 8$ & $1511 \cdot 7$ & $2104 \cdot 7$ & $0 \cdot 07$ \\
\hline Polyphenols (mg/d) & 913.7 & $522 \cdot 7$ & 1229.9 & $1148 \cdot 8$ & $658 \cdot 56$ & $1386 \cdot 8$ & $0 \cdot 10^{\mathrm{a}}$ \\
\hline Potassium intake $(\mathrm{g} / \mathrm{d})$ & $3 \cdot 19$ & $2 \cdot 28$ & $3 \cdot 70$ & 3.49 & $2 \cdot 57$ & 3.94 & $0 \cdot 26^{\mathrm{a}}$ \\
\hline Fruits $(\mathrm{g} / \mathrm{d})$ & $216 \cdot 1$ & $84 \cdot 5$ & $249 \cdot 4$ & $215 \cdot 8$ & 71.4 & $285 \cdot 4$ & $0 \cdot 86^{\mathrm{a}}$ \\
\hline Vegetables $(\mathrm{g} / \mathrm{d})$ & $212 \cdot 0$ & $78 \cdot 4$ & $266 \cdot 7$ & $232 \cdot 33$ & $136 \cdot 22$ & $311 \cdot 2$ & $0.72^{\mathrm{a}}$ \\
\hline Fluids intake (L/d) & $2 \cdot 52$ & $1 \cdot 87$ & $3 \cdot 20$ & 2.47 & 1.90 & 2.99 & $0 \cdot 59$ \\
\hline
\end{tabular}

*Data is normally distributed and presented as mean and standard deviation. p-values between-group comparisons were calculated using Mann-Whitney U Test. ${ }^{a}$ Adjusted for energy intake.

Potassium intake should only be limited if blood tests shows it to be necessary; it was the case in only $8 \%(n=7)$ T2DM patients $(5.5-6.1 \mathrm{mM})$; with a further $17 \%(\mathrm{n}=15)$ under angiotensin-converting enzyme inhibitors that may precipitate hyperkalaemia. There are no specific dietary recommendations for patients with early CKD; $18 \%(\mathrm{n}=16)$ reported to restrict dietary potassium and $30 \%$ $(\mathrm{n}=26)$ had visited a dietitian at least once in the preceding year. Energy intake was below the adult reference intake $(2,000 \mathrm{kcal} / \mathrm{d})$ and is likely to indicate underreporting $-70 \%(\mathrm{n}=61)$ of CKD subjects did not meet general dietary recommendation for potassium (RNI $3.5 \mathrm{~g} / \mathrm{d})$ and $57 \%(\mathrm{n}=50)$ for fruit and vegetable intake $(400 \mathrm{~g} / \mathrm{d})^{(5)}$, compared to $40 \%$ in controls who did not meet the recommendations for both. Fruits and vegetable intake contributed toward $28 \%$ of the total potassium intake followed by dairy products $(18 \%)$ and meat products $(12 \%)$. T2DM patients' potassium excretion was $9 \%$ lower than controls. Some fruits and vegetables are low in potassium, high in polyphenols and could represent an opportunity for intervention. Long-term trials in early CKD patients investigating polyphenol and potassium intake on renal biomarkers and clinical outcomes are needed to address dietary recommendations and reduce the progression of the disease.

S.A.P-D acknowledges PhD scholarship funding by Mexican National Council for Science and Technology.

1. Pugliese G, Solini A, Bonora E et al. (2014) Nutr Metab Cardiovasc Dis 24, 815-822.

2. Khangholi S, Fadzilah A. M, Berwary N J et al. (2015) Planta Medica 82, 32-45.

3. Snelson M, Clarke R, Coughlan M et al. (2017) Nutrients 9, 265

4. Kawasaki T, Ithoh K, Uezono K et al. (1993) Clin Exp Pharmacol Physiol 20, 7-14

5. Thomas B (2001) Manual of dietetic practice: Blackwell Science. 